\title{
The Healthy Benefits of Isolating Earphones
}

Jérémie Voix, Cécile Le Cocq, and Lee D. Hager

Citation: Proc. Mtgs. Acoust. 4, 050003 (2008); doi: 10.1121/1.2979231

View online: https://doi.org/10.1121/1.2979231

View Table of Contents: https://asa.scitation.org/toc/pma/4/1

Published by the Acoustical Society of America

\section{ARTICLES YOU MAY BE INTERESTED IN}

Characteristics of noise-canceling headphones to reduce the hearing hazard for MP3 users

The Journal of the Acoustical Society of America 131, 4526 (2012); https://doi.org/10.1121/1.4707457

The effects of environmental and classroom noise on the academic attainments of primary school children

The Journal of the Acoustical Society of America 123, 133 (2008); https://doi.org/10.1121/1.2812596

No correlation between headphone frequency response and retail price

The Journal of the Acoustical Society of America 141, EL526 (2017); https://doi.org/10.1121/1.4984044

Disability rights aspects of ambient noise for people with auditory disorders under the Americans with Disabilities Act

Proceedings of Meetings on Acoustics 31, 015001 (2017); https://doi.org/10.1121/2.0000657

Application of the remote microphone method to active noise control in a mobile phone

The Journal of the Acoustical Society of America 143, 2142 (2018); https://doi.org/10.1121/1.5031009

Acoustic mechanisms that determine the ear-canal sound pressures generated by earphones

The Journal of the Acoustical Society of America 107, 1548 (2000); https://doi.org/10.1121/1.428440

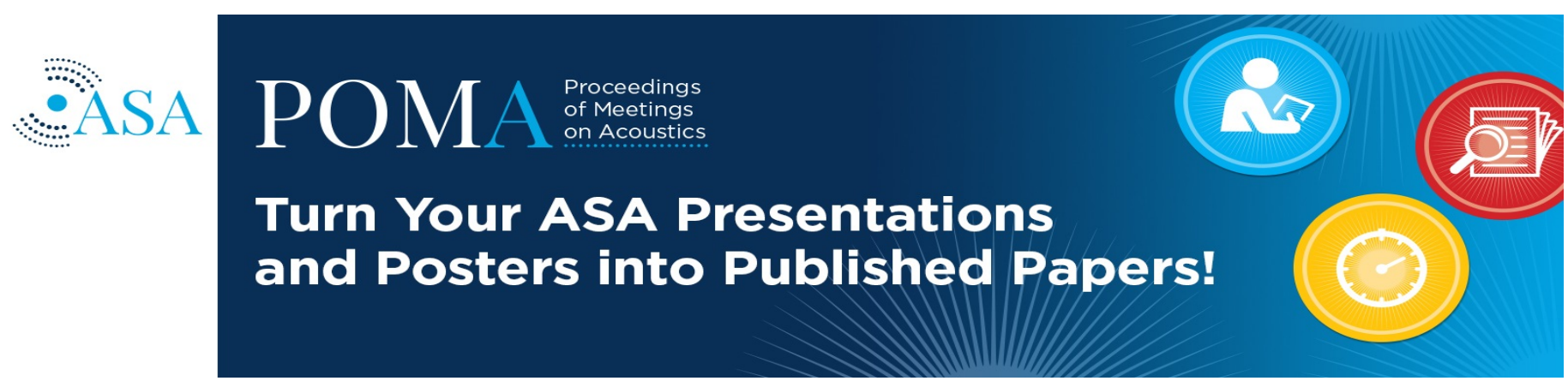




\section{Proceedings of Meetings on Acoustics}

\section{5th Meeting \\ Acoustical Society of America}

Paris, France

29 June - 4 July 2008

\section{Session 3pPPb: Psychological and Physiological Acoustics}

\section{3pPPb4. The Healthy Benefits of Isolating Earphones}

\section{Jérémie Voix, Cécile Le Cocq and Lee D. Hager}

With the ubiquitous presence of Personal Stereo Players (PSPs), namely iPods(R) and the like, many hearing conservationists have raised concerns about the temporary and permanent hearing damages that could result from long exposure to loud music playback, especially among adolescents and teenagers. The crux of the problem can be identfied as an overexposure of the auditory system. In order to reduce the dose received by the PSP listener, the playback level and/or the duration should be reduced. Assuming that the duration of the music playback experience is really up to the user, the remaining parameter is the music playback level. The purpose of this study is to first understand - from the available public and scientific literature - what factors are influencing the PSP playback level; and second, to investigate if the use of earphones featuring good attenuation of the ambient noise level would lead to a reduced playback level, hence a reduced dose and eventually less auditory damage. Other benefits on sound quality that are associated with isolating earphones will be presented in a third part. Finally the article will review other safety mechanisms that could be used in earphones and PSP to make them safe for the hearing.

Published by the Acoustical Society of America through the American Institute of Physics 


\title{
The healthy benefits of isolating earphones
}

\author{
Jérémie Voix ${ }^{a}$,Eng., Ph.D., Cécile Le Cocq ${ }^{b}$,Jr. Eng., L. D Hager ${ }^{a}$ \\ ${ }^{a}$ Sonomax Hearing Healthcare Inc, 8375 Mayrand, QC H4P 2E2 Montreal, Canada \\ ${ }^{b}$ Ecole de Technologie Superieure, 1100 Notre-Dame Ouest, QC H4P 2E2 Montreal, Canada \\ jvoix@sonomax.com
}

\section{Introduction}

MP3 players, Portable Multimedia Players and Smart Phones with audio playback capabilities, commonly referred to in this article as "Personal Stereo Systems" (PSSs) are very widely used in the developed world, especially adolescents and teenagers. Indeed, worldwide unit shipments for PSSs reached 182 million in 2006, up $42 \%$ from 2005 and are expected to grow to 275 million units by 2011 [1]. The daily noise dose accumulated with the use of such music playback systems incrementally adds to occupational noise exposure and the combination may result in excessive noise exposure. Even if the safety (from an auditory perspective) of such practice has been questioned [2] since the 1980's (beginning with the introduction of the Sony WalkMan ${ }^{\mathrm{TM}}$ ), not many answers nor practical tools have been developed to reduce or manage the risk of Noise Induced Hearing Loss.

The purpose of this study is to first understand from the available public and scientific literature what factors influence the PSS playback level; and second, to investigate if the use of earphones featuring good attenuation of the ambient noise level would lead to a reduced playback level, hence a reduced dose and potentially less auditory damage.

The first section presents analysis of the useage habits of PSS users in terms of listening level and listening time and the influence of background noise. The second section describes the actual remedies or potential changes in PSS use habits that may assist in reducing risk. The third section describes in detail one specific application (the Sonomax solution, a custom expandable isolating earphone).

\subsection{Personal stereo systems (PSSs): a risk for the hearing}

A number of factors can explain why the use of PSSs is so common and why they may pose a danger to hearing health. Axelsson [3] explains the convenience of these portable devices with high sound levels capabilities, the feeling of "being inside the music" with high sound levels, the good impulsive sound reproduction, the fact that since they are relatively quiet to others than the user/listener, they do not disturb the environment (hence few complaints from neighbors). On the hazardous side, he also noted that users tend to turn up sound levels in noisy environments, and that exposure duration may be quite long, resulting in PSSs users having poorer hearing than non users. Potentially even more damaging is that Axelsson found that users with temporary threshold shift may compensate by turning up the volume on their PSS!

\subsubsection{Listening level}

The sound pressure levels (SPL) at maximal power output for PSSs can be quite high. Fligor and Cox [4] measured SPL between 95 and 120dBA. The World Health Organization (WHO) stipulates that in order to avoid acute hearing impairment LAmax should always be below $110 \mathrm{dBA}$ [5], making the use of PSSs at full power problematic [6, 7]. Hopefully, users are rarely using the PSSs at their maximum levels, but still, the Royal National Institute for Deaf People [7] reported that $65 \%$ of users were listening at levels above $85 \mathrm{~dB}$, while Rice et al. [8] reported that $20 \%$ of the users tested had a preferred listening level (PLL) higher than $90 \mathrm{~dB}$. It is reasonable to assume that a too high listening level in itself is not a danger for the hearing of a majority of users.

\subsubsection{Listening time and accumulated noise dose}

It is apparently not the listening level alone that is the danger, but rather the combination of a high listening level and listening time, which constitutes the noise dose. While the WHO recommends [5] limiting dose to $70 \mathrm{dBA}$ for a $24 \mathrm{~h}$ period or to $85 \mathrm{dBA}$ for a $1 \mathrm{~h}$ period, the study conducted by the Royal National Institute for Deaf People reported that more than $50 \%$ of the people surveyed reported listening their PSSs for more than $1 \mathrm{~h}$ per day. Accordingly if these users are exceeding a level of $85 \mathrm{dBA}$, they are putting their hearing at risk. Catalano and Levin [2] have compared the dose received by PSS users to the maximal dose advised by the American Academy of Ophthalmology and Otolaryngology (85 dBA for $16 \mathrm{~h}$ per day or $80 \mathrm{~h}$ per week over 10 years) and found that $31.4 \%$ of the users exceeded that criteria.

\subsection{Relation between the background noise level and the listening level}

One of the first studies on background noise influence on PLL was made by Rice et al. in 1987 [9]. This study found that in silence the PLL for the studied population was $80.7 \mathrm{~dB} L_{A e q}$. With road traffic background noise of $70 \mathrm{dBA}$ the PLL was $85.1 \mathrm{~dB} L_{A e q}$, giving a $15 \mathrm{~dB}$ signal to noise ratio (SNR).

In 2005, Williams [10] interviewed PSS users in the street about their PLL habits. In average background noise of $73.2 \mathrm{dBA}$ (standard deviation $2.3 \mathrm{~dB}$ ), the average PLL is $86.1 \mathrm{~dB} L_{A e q, 2 h}(7.9 \mathrm{~dB}$ of standard deviation), resulting in SNR of about $13 \mathrm{~dB}$.

In 2007, Hodgetts and all [11] examined the relationship between background noise (quiet, street noise between 70 and $80 \mathrm{dBA}$, multi-talker babble at $70 \mathrm{dBA}$ ), ear- 
phones types (in-the-ear, over-the-ear, over-the-ear with noise cancelling) and PLL. Their subjects were university students and testing was performed in a laboratory. Table 1 presents their results: average PLL in $L_{A e q}$, standard deviation in brackets and estimated SNR. Whatever the ear-

Table 1: Results (mean ear canal level in dBA (standard deviation) SNR) extract from [11]

\begin{tabular}{|l|c|c|c|}
\hline & Quiet & $\begin{array}{c}\text { Multi-talker } \\
\text { babble } \\
70 \mathrm{dBA}\end{array}$ & $\begin{array}{c}\text { Street } \\
\text { noise } \\
70 \mathrm{to} \\
80 \mathrm{dBA}\end{array}$ \\
\hline In-the-ear & 77.82 & 86.66 & 88.83 \\
& $(7.7)$ & $(4.3)$ & $(3.9)$ \\
& & $\approx 17 \mathrm{~dB}$ & $\approx 14 \mathrm{~dB}$ \\
\hline Over-the-ear & 75.17 & 82.93 & 84.46 \\
& $(9.5)$ & $(5.5)$ & $(4.8)$ \\
& & $\approx 13 \mathrm{~dB}$ & $\approx 9 \mathrm{~dB}$ \\
\hline Over-the-ear/NR & 75.16 & 81.63 & 83.00 \\
& $(9.1)$ & $(5.6)$ & $(5.4)$ \\
& & $\approx 12 \mathrm{~dB}$ & $\approx 8 \mathrm{~dB}$ \\
\hline
\end{tabular}

phone type used, higher background noise levels resulted in higher PLL and lower SNR. Moreover, the over-theear earphone with noise cancelling resulted in a reduction in PLL. The results from the two first studies from Rice and all. [9] and Williams [10] match the results of the earphones without noise cancelling.

In 1996, Airo et al. [12] examined background noise influence on PLL in both a laboratory and field study with earphones without noise attenuation. In the laboratory, railway station, subway train cabin, traffic on a busy street, industrial noise and pink noise were considered at $L_{A e q}$ of $60,70,80$ and $90 \mathrm{~dB}$. In the field, public places and streets were chosen. Table 2 shows the average results of: background noise level, PLL in $L_{A e q}$ and SNR, with standard deviations in brackets. Airo et al.

Table 2: Average background noise levels, PLLs and SNR in field, laboratory and combined measurements, with standard deviation in square brackets, extract from

\begin{tabular}{|l|c|c|c|}
\hline & Field & Laboratory & Combined \\
\hline Noise $[\mathrm{dBA}]$ & $65(4.8)$ & $73(11)$ & $71(10.3)$ \\
\hline PLL $\left[\mathrm{dB} L_{A e q}\right]$ & $82(8.8)$ & $85(6)$ & $84(6.9)$ \\
\hline SNR $[\mathrm{dB}]$ & $17(8)$ & $12(7.2)$ & $14(7.6)$ \\
\hline
\end{tabular}

determined the linear regression in all three cases (field, laboratory and combined). The Airo et al. data will be more thoroughly discussed later in paper.

Based on this short literature review:

- Any PSS can emit damaging sound levels;

- Most of PSS users have an acceptable PLL in quiet settings;

- Background noise level has a significant influence on PLL;

- PSS users favor the music quality (not too loud) rather than the SNR;
- The average preferred SNR is about $13 \mathrm{~dB}$;

- Airo et al recommend that "continuous use of PSS and earphones should be avoided in conditions where environmental noise level exceeds $70 \mathrm{~dB}$ ".

It should be noted that the average noise level in the New-York subway is $85.7 \mathrm{dBA}$, with peaks as high as 112 dBA [13]. However, Ario et al. [12] recommend not using PSS in a background noise higher than $70 \mathrm{~dB}$. Indeed with such levels, is would be expected that the PLL will be set higher than the WHO recommendation of $85 \mathrm{dBA}$ for one hour [5].

\section{Solutions to PSS danger}

Various options are available to limit the danger of PSSs for user's hearing health.

\subsection{Inform PSSs users}

Raising public awareness on the potential of auditory risks caused by abuse of PSSs is essential. Health Canada is warning the public of the auditory damage possibly caused by the abuse of PSSs [14]. The Royal National Institute for Deaf People suggests that PSSs manufacturers put warnings on their products [7], just as required in the tobacco industry. Laroche et al. [15] are currently evaluating a temporary threshold shift detector [16] that could be run on PSSs intended to warn the user about auditory risk.

\section{$2.2 \quad$ Limit the listening level}

Some jurisdictions are promulgating rules regarding limitation on PSS maximum levels. In France, in 1998, maximum SPL has been limited to $100 \mathrm{~dB}$ [17] and more recently, in 2005, output voltage has been limited to $150 \mathrm{mV}$ [18]. Some simple handheld devices have been commercialized, like the Ear 3 (Hollins Communications Research Institute, VA, USA), to help protect people from hearing loss by measuring sound levels and indicating when PSS emit potentially damaging levels of noise. Unfortunately, the absolute level on its own is rarely the cause of hearing damage, and listening time has also to be taken into account.

\subsection{Limit the listening time and the ac- cumulated noise dose}

Several "rules of thumb", such as a playback level at $60 \%$ of maximum for 60 minutes only [4], have been developed to attempt to limit both the listening level and the listening time, and hence to limit the accumulated noise dose. Rules such as these are unfortunately very gross approximations since they cannot account for the difference in the power output of the PSSs nor the sensitivity of the earphones used by the user.

\subsection{Use noise isolating earphones}

Given that the listening level appears to be mostly related to the level of the background noise, the use of earphones that provide some degree of attenuation of the ambient noise may help the user reduce the listening level. 


\subsubsection{Active noise reduction of the background noise}

Some earphones featuring active noise reduction (ANR) have been recently commercialized [19], like the QuietComfort $\AA$ Acoustic Noise Cancelling $\AA$ Headphones from Bose Corporation (MA, USA). These ANR earphones generally use a feedback controller to generate a sound wave that is of the same magnitude but opposite phase as the initial disturbance (the background noise). They can quite effectively cancel or reduce the background noise in the area of the user's ears. There limitations are two-fold. On the performance side, the active controller is only effective on a limited frequency range and does not effectively cancel or attenuate the high frequency content of the background noise. The technology is also ineffective for noises with too highly fluctuating characteristics, such as human speech. From the perspective of comfort, since the high pitched background has to be attenuated by passive means (like a circumaural headset), the ANR headset may be quite bulky.

\subsubsection{Passive attenuation of the background noise}

Another approach consist is merging the features of the earphone with the noise isolation provided by a passive hearing protection device. Such earphone can be a headset or an intra-canal generic "one-size-fits-most" earpiece, such as the Etymōtic Research Inc. (IL, USA) ER6 Isolator $^{\mathrm{TM}}$ earphones. This is the approach that has been used in the current proposal and that will be further discussed in terms of pro's and con's in the following section.

\section{A custom expandable isolating earphone}

Fig. 1 presents the custom expandable isolating earphone as designed by Sonomax Hearing Healthcare Inc. (QC, Canada), a manufacturer of custom instantly-fitted earplugs. The earpiece is instantly adjusted to the ear canal by the injection of a two-part medical silicon filler into a very thin inflatable envelope which surrounds a soft silicone core of generic shape and size. This unique feature ensures a custom and comfortable fit of the earpiece and secures it inside the wearer's earcanal. The soundbore that holds the speaker housing (visible in Fig.1 on the soft silicone core) is first used to insert a specially-developed microphone for the measurement of the difference between the sound pressure levels outside the earpiece and in the occluded earcanal (see [20] for the assessment of the earpiece attenuation), to assess the quality of the acoustic seal. This testing feature ensures the user that his custom expandable earphone is not only providing a good sound isolation but also optimize the low-frequency response of the miniature receiver used.

\subsection{The benefits of custom isolating ear- phone}

Apart from the physical comfort benefits discussed previously, the main auditory benefit of the custom isolating

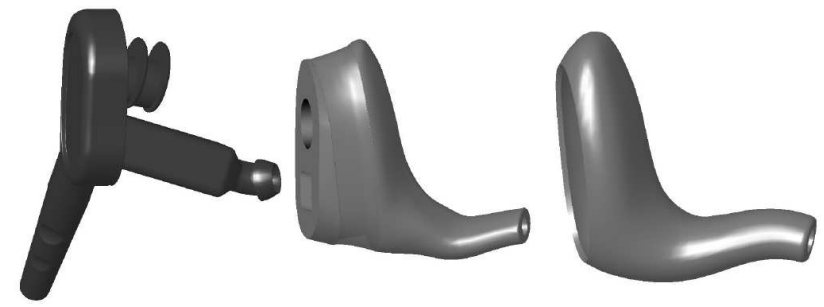

Figure 1: Exploded view of the custom expandable isolating earphone (not yet adjusted to the earcanal): transducer housing (left), soft silicone core (middle) and inflatable envelope (right).

earphone is reduced background noise, hence the reduced PLL. To illustrate that decrease of the music playback level, a statistical analysis will be conducted on athorough dataset made available by Airo et al. [12] on earphones not providing any noise isolation.

Fig. 2 shows the linear regression between the background noise levels and music listening levels as well as the $95 \%$ confidence bands for these data. Fig. 3 illustrates

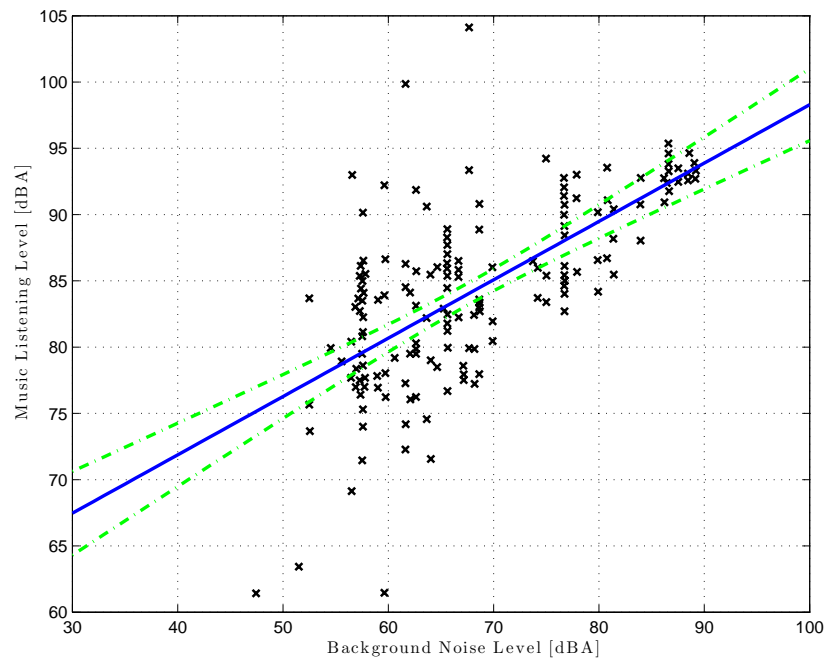

Figure 2: Linear regression fitting and the $95 \%$ confidence bands for background noise levels and music listening levels (free-field equivalent sound pressure levels) with the data extracts from [12]

the auditory benefits of using the Sonomax isolating earphone, featuring a $N R S_{A 50 \%}=26 \mathrm{~dB}$ attenuation (see [21] for details on NRS calculations): for an average background noise of $67.9 \mathrm{dBA}$ the average PLL is $84.2 \mathrm{~dB} L_{A e q}$, but since the background noise is now reduced by the amount of attenuation provided by the isolating earphone (down to $41.9 \mathrm{dBA}$ ), the PLL is now accordingly reduced to $72.7 \mathrm{~dB} L_{\text {Aeq }}$. Fig. 4 shows the distribution of the PLL both for a PSS with non-attenuating earpieces (in blue) and for a isolating PSS featuring a $N R S_{A 50 \%}=26 \mathrm{~dB}$ noise attenuation (in red). The benefits of the isolating earphone are evident: using a non-isolating PSS, $45.1 \%$ of the users have a PLL higher than $85 \mathrm{~dB} L_{A e q}$ (the rec- 


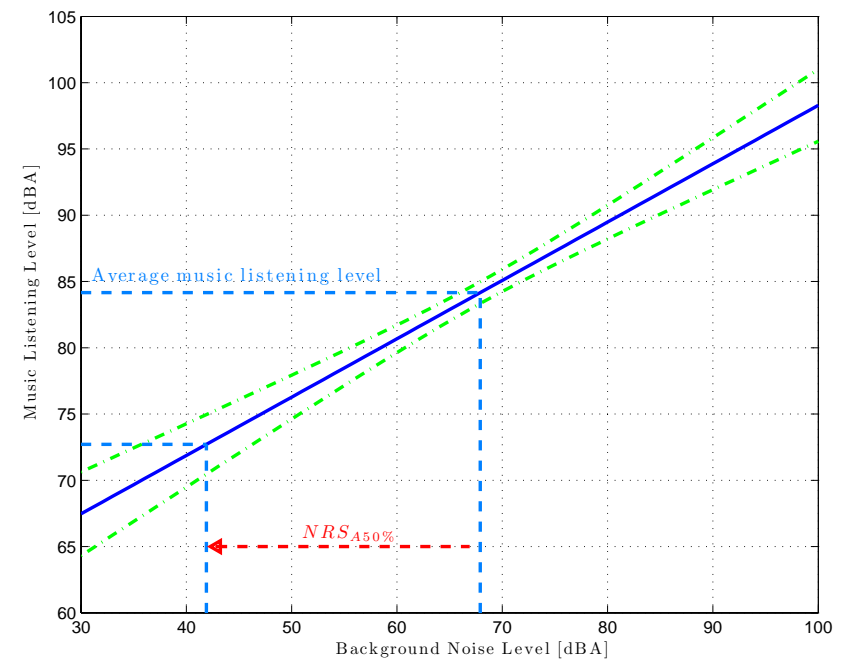

Figure 3: Linear regression fitting and the $95 \%$ confidence bands for background noise levels and music listening levels and the application of the $N R S_{A 50 \%}$

ommended maximum level for one hour listening without risk of hearing losses based on WHO recommendations), while this value drops to $3.7 \%$ of the users if the PSS used earpieces with an $N R S_{50 \%}=26 \mathrm{~dB}$ sound isolation, like the Sonomax custom expandable isolating earphone.

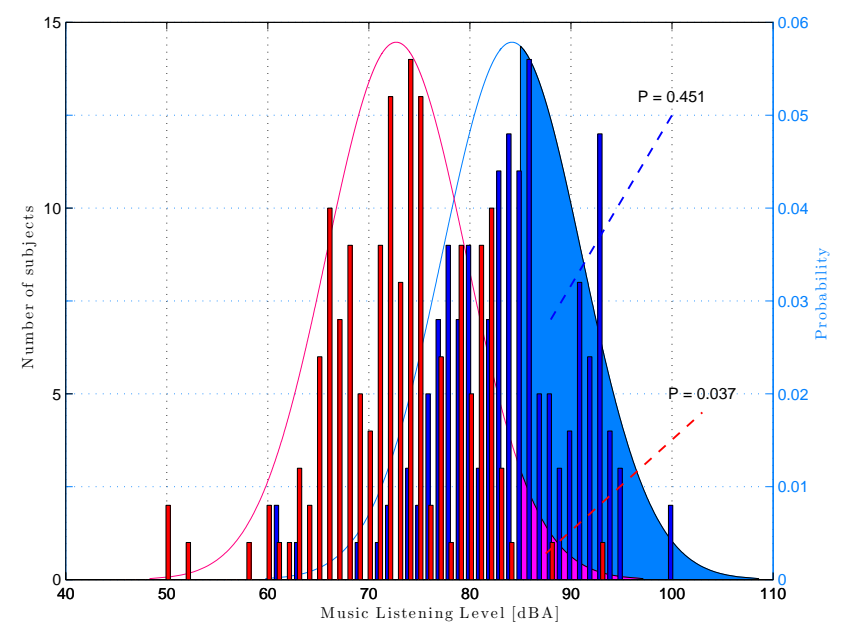

Figure 4: Distribution of the music listening levels with and without the NRS application

\subsection{Safety concerns associated with the isolating earplugs}

The reduced PLL associated with the use of such a custom isolating earphone is associated with the fact that good passive attenuation is offered by the earpiece. This can also raise some concerns regarding the safety of using such isolating earpiece with a PSS in day-to-day activities.

Given that simply driving a car while listening to the radio can create a distraction (see [22]), it is no surprise that the use of portable electronic devices (such as cellphone or PSS) can more greatly increase distractions. Pedestrians are also clearly distracted when using such electronic de- vices [23], and their proved inability to concentrate properly $[24,25,26]$ can even be the reason for lethal injuries [27] in up to $15 \%$ of pedestrian/vehicle incidents.

Use of isolating earphones with a PSS could clearly lead to similar distraction, but one could also fear that some useful auditory cues (like the noise of an approaching motorized vehicle [28]) might be masked and further jeopardize the user's safety. Although some very recent studies [29] suggested that pedestrians using a PSS were actually behaving more safely than cellphone users and even more safely than regular pedestrians, such unexpected outcome is most probably due to an extra cautiousness of the user and required further scrutiny. Meanwhile most of the manufacturers should warn, if they do not already do so, the users of noise isolating earphone against using their use in activities where auditory cues can be crucial (street jogging, car driving, etc.).

\section{Conclusions}

Risks associated with Personal Stereo Systems (PSSs) use have been explored and some existing solutions have also been presented. Given that the preferred listening level (PLL) is, for a given individual, essentially driven by the background noise level, the use of noise isolating earphone appears as a logical first step. The auditory benefits of such isolating earphone use has been further examined by evaluating the reduction of the PLL associated with the use of an isolating earphone. A concept of a custom expandable instantly-fitted earphone featuring an average $26 \mathrm{~dB}$ attenuation has been presented. Using a simple statistical analysis on existing published data, the percentage of wearers using a regular non-isolating earphone exposed to a potentially dangerous noise dose has been established to $45.1 \%$. The use of the proposed custom isolating earphone would lead theoretically to a substantial decrease (down to $3.1 \%$ ) of the percentage of users putting their hearing at risk. While it remains unclear if the use of such isolating earphones is increasing or not, the risk for the user of physical injury due to an auditory warning mis-perception, the precaution principle should be applied. The use of noise isolating earphones can bring healthy benefits to PSS users, as long as they are not used in activities where hearing of auditory cues is critical.

\section{References}

[1] Stephanie Ethier. Worldwide demand remains strong for $\mathrm{mp} 3$ and portable media players. Technical report, In Stat, Portable entertainment devices, August 2007.

[2] Peter J. Catalano and Stephen M. Levin. Noiseinduced hearing loss and portable radios with headphones. International journal of pediatric otorhinolaryngology, 9(1):59-67, 1985.

[3] A. Axelsson. Recreational exposure to noise and its effects. Noise control engineering journal, 44(3):127$134,1996$. 
[4] Brian J. Fligor and L Clarke Cox. Output levels of commercially available portable compact disc players and the potential risk to hearing. Ear and hearing, 25(6):513-527, 2004.

[5] WHO. Guidelines for community noise. Technical report, 1999.

[6] Pauline A. Smith, Adrian Davis, Melanie Ferguson, and Mark E. Lutman. The prevalence and type of social noise exposure in young adults in england. Noise health, 2(6):41-56, 2000.

[7] Mp3 generation face premature hearing damage, rnid warns. RNID (The Royal National Institute for Deaf People), 2007.

[8] C. G. Rice, G. Rossi, and M. Olina. Damage risk from personal cassette players. British journal of audiology, 21(4):279-288, 1987.

[9] C. G. Rice, M. Breslin, and R.G. Roper. Sound levels from personal cassette players. British journal of audiology, 21(4):273-278, 1987.

[10] Warwick Williams. Noise exposure levels from personal stereo use. International journal of audiology, 44(4):231-236, 2005.

[11] William E. Hodgetts, Jana M. Rieger, and Ryan A. Szarko. The effects of listening environment and earphone style on preferred listening levels of normal hearing adults using an mp3 player. Ear and hearing, 28(3):290-297, 2007.

[12] E. Airo, J. Pekkarinen, and P. Olkinuora. Listening to music with earphones: an assessment of noise exposure. Acustica - Acta Acustica, 82:885-894, 1996.

[13] Robyn R. M. Gershon, Richard Neitzel, Marissa A. Barrera, and Muhammad Akram. Pilot survey of subway and bus stop noise levels. Journal of Urban Health: bulletin of the New York academy of medicine, 83(5):802-812, 2006.

[14] It's your health - personal stereo systems and the risk of hearing loss. Health Canada, 2006. Santé Canada Votre santé et vous Le baladeur et le risque de perte auditive.

[15] Chantale Laroche, Christian Giguère, L. Blomberg, V. Vaillancourt, J. Séguin, and V. Lizée. Development of temporary threshold shift detector for use in ipods and other portable audio devices. In Congrès annuel de l'ACA, Montréal, Québec, Canada, 2007. CAA-ACA.

[16] Leslie D. Blomberg. United states patent application 20080015464 - temporary threshold shift detector, 2008.

[17] France. Article 1. 44-5 du code de la santé publique relatif aux baladeurs musicaux, 1998.
[18] France. Article 1. 5232-1 du code de la santé publique relatif aux baladeurs musicaux, 2005.

[19] Mayo Clinic Staff. Hearing loss: Mp3 players can pose risk. Tools for healthier lives, 2007(18/10/2007), 2006.

[20] Jeremie Voix and Frederic Laville. Expandable earplug with smart custom fitting capabilities. The 2002 International Congress and Exposition on Noise Control Engineering Dearborn, MI, USA. August 1921, 2002, 2002.

[21] Acoustics Accredited Standards Committee S1. ANSI S12.68-2007 AMERICAN NATIONAL STANDARD Methods of Estimating Effective A-Weighted Sound Pressure Levels When Hearing Protectors are Worn. 2007.

[22] L. Jancke, F. Musial, J. Vogt, and KT. Kalveram. Monitoring radio programs and time of day affect simulated car-driving performance. Perceptual and motor skills, 79(1):484-486, 1994.

[23] Julie Hatfield and Susanne Murphy. The effects of mobile phone use on pedestrian crossing behaviour at signalised and unsignalised intersections. Accident analysis $\mathcal{B}$ prevention, 39(1):197-205, 2007.

[24] Z. Tabibi and K. Pfeffer. Choosing a safe place to cross the road: the relationship between attention and identification of safe and dangerous roadcrossing sites. Child: Care, Health and Development, 29(4):237-244, 2003.

[25] D. Whitebread and K. Neilson. Learning to cross the road: cognition in action. Psychologist, 12(8):403405, 1999. Web of science.

[26] Marjorie Woollacott and Anne Shumway-Cook. Attention and the control of posture and gait: a review of an emerging area of research. Gait \& Posture, 16(1):1-14, 2002.

[27] Timothy J. Bungum, Charlene Day, and L. Jean Henry. The association of distraction and caution displayed by pedestrians at lighted crosswalk. Journal of community health, 30(4):269-279, 2005.

[28] Michael S. Wogalter, Rachelle N. Ornan, Raymond W. Lim, and M. Ryan Chipley. On the risk of quiet vehicles to pedestrians and drivers. In Proceedings of the Human Factors and Ergonomics Society 45th Annual Meeting, pages 1685-1688, Minneapolis/St.Paul, MN, United States, 2001. Human Factors an Ergonomics Society Inc.

[29] Jack Nasar, Peter Hecht, and Richard Wener. Mobile telephones, distracted attention, and pedestrian safety. Accident analysis 83 prevention, 40(1):69-75, 2008 . 